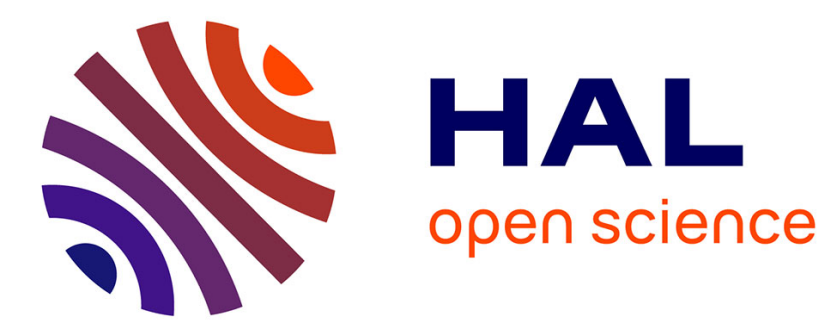

\title{
A uniaxial cyclic compression method for characterizing the rheological and textural behaviors of mechanically dewatered sewage sludge
}

Fenglin Liang, Martial Sauceau, Gilles Dusserre, Patricia Arlabosse

\section{- To cite this version:}

Fenglin Liang, Martial Sauceau, Gilles Dusserre, Patricia Arlabosse. A uniaxial cyclic compression method for characterizing the rheological and textural behaviors of mechanically dewatered sewage sludge. Water Research, 2017, 113, pp.171-180. 10.1016/j.watres.2017.02.008 . hal-01619250

\section{HAL Id: hal-01619250 \\ https://hal.science/hal-01619250}

Submitted on 24 Nov 2017

HAL is a multi-disciplinary open access archive for the deposit and dissemination of scientific research documents, whether they are published or not. The documents may come from teaching and research institutions in France or abroad, or from public or private research centers.
L'archive ouverte pluridisciplinaire HAL, est destinée au dépôt et à la diffusion de documents scientifiques de niveau recherche, publiés ou non, émanant des établissements d'enseignement et de recherche français ou étrangers, des laboratoires publics ou privés. 
A uniaxial cyclic compression method for characterizing the rheological behavior of mechanically dewatered sewage sludge Fenglin Liang ${ }^{1}$, Martial Sauceau $^{1}$, Gilles Dusserre ${ }^{2}$ and Patricia Arlabosse ${ }^{1}$ Corresponding author: Patricia.Arlabosse@mines-albi.fr

${ }^{1}$ Université de Toulouse; Mines Albi; CNRS; Centre RAPSODEE, Campus Jarlard, 81013 Albi, France

${ }^{2}$ Université de Toulouse; CNRS, Mines Albi, INSA, UPS, ISAE-SUPAERO; ICA (Institut Clément Ader); Campus Jarlard, F-81013 Albi, France

\begin{abstract}
The mechanically dewatered sewage sludge with total solid content around $20 \%$ on a weight basis is very similar to yield stress fluid, its complex transition between solid and fluid states is not perfectly reversible and especially challenging in terms of pumping, land spreading and drying. To characterize the rheological and textural properties of highly concentrated sludge, a specific methodology based on uniaxial single and cyclic compression tests is developed. Three types of sludge samples (fresh original, fresh premixed and aged original ones) are extruded into cylinders and pressed between two parallel plates using a material testing machine. In single compression, the bioyield point is around $7.3 \mathrm{kPa}$ with true strain equal to 0.21 beyond which the sludge fractures. The cyclic compression tests reveal that the sludge behaves as a viscoelastic body when the true strain is smaller than 0.05 . Once exceeding the yield stress, it behaves as a visco-elasto-plastic one. The elastic module is around $78 \mathrm{kPa}$; the viscosity is deduced, in the order of magnitude $10^{4}$ to $10^{5} \mathrm{~Pa} . \mathrm{s}$ and the yield stress is estimated about $4 \mathrm{kPa}$. In the unloading phase, the sludge behaves again as a viscoelastic body with clear hysteresis. With the increase of compression speed, the viscosity declines. This confirms that the sludge is a shear-thinning material. The yield stress and the bioyield increase with compression speed, but it does not induce extra internal damage in the samples since the resilience and the cohesiveness are unaltered. The reliability and sensitivity of the method is justified by highlighting the changes of sludge behavior induced by aging and premixing: both decrease the strain energy density, but do aggravate the adhesiveness of the sludge; the aging makes the sludge less cohesive, while the premixing does not modify its cohesiveness. In spite of changes in test conditions, the elastic module of sludge samples remains unchanged.
\end{abstract}

Keywords

Rheology, visco-elasto-plastic, yield, texture, aging, premixing 


\section{Introduction}

In volume, sewage sludge is the largest by-product recovered in a municipal wastewater treatment plant (WWTP). Typically, these solids and biosolids are in the form of a liquid or semisolid liquid, which contain from 0.25 to $5 \%$ of solid by weight. Thickening, conditioning and mechanical dewatering are necessary treatments to remove the moisture, which reduces the volume, improves the handling, facilitates the storage and decreases the transport costs for further valorization. In Europe, most of the municipal WWTPs implement these treatments to best achieve a total solid content (TS) around 18 to $25 \%$ with a continuous dewatering process. Most of the dewatered sludge maintains its shape in the same way as a solid under the effect of gravity but is able to flow like a fluid, i.e. a substance that continuously deforms, when submitted to a high enough stress. These soft materials are very similar to yield stress fluids. But the key difference is that the highly concentrated sludge cannot recover the properties it had before flowing in the liquid regime: the transition between solid and fluid states is not perfectly reversible (Coussot, 2014). Sludge processing, reuse and disposal are among the most complex technical problems facing the engineers in the field of wastewater treatment. This complex transition between solid and fluid states is especially challenging in terms of pumping, land spreading and drying (Baudez et al., 1998). Concurrently, the inevitable impacts of aging (due to the degradation of organic matters) and premixing (including shearing, pressing and squeezing induced by pumping, transporting and other mechanical handlings) modify more or less the rheological and textural behaviors of sludge. Papadakis and Bahu (1992) reported the crucial sludge stickiness to equipment surfaces observed in drying processes. The sticking accumulation may lead to significant reduction of dehydration capacity and efficiency (Beckley and Banerjee, 1999; Jing et al., 1999; Kudra, 2003; Ohm et al., 2009). Therefore, the characterization of rheological and textural behaviors of mechanically dewatered sewage sludge is aimed to settle the dominant properties with respect to operational conditions so as to optimize the processing design.

The main factors dominating the sewage sludge properties are the temperature (Lotito and Lotito, 2014; Feng et al., 2014; Dai et al., 2014; Battistoni, 1997; Baroutian et al., 2013; Baudez et al., 2013; Farno et al., 2014; Mori et al., 2006), the composition and the microstructure (Ruiz and Wisniewski, 2008; Lin et al., 2013; Nielsen et al., 1996; Pevere et al., 2009; O'Kelly, 2008; Baudez and Coussot, 2001; Baudez, 2008; Agoda-Tandjawa et al., 2013; Mori et al., 2008; Ma et al. 2014) as well as the solid concentration. Until 2013 (Seyssiecq et al., 2003; Eshtiaghi et al., 2013), most of the rheological characterization studies were focused on sludge in liquid to pasty states $(1.5 \%<\mathrm{TS}<15 \%)$. Rheometers have always been the mainstream tool. Unfortunately, an effective standard specifically designed for sludge, that includes both sample preparation and characterization, is lacking. Considering the large number of operating parameters, such as the geometry, gap size, wall surface roughness and pre-shearing rate, it is not possible to get an absolute value for the viscosity (Ratkovich et al., 2013) and the yield stress (Jiang et al., 2014). Few publications are devoted to the characterization of pasty sludge having TS higher than 15\%. Jiang et al. (2014) carried out both steady flow and dynamic oscillatory measurements to investigate the impact of both solid content and temperature. These measurements were all conducted on a conventional rotating rheometer. Even at TS $=16 \%$, the sludge was flowable under tangential stress. The same observation was reported by Agoda-Tandjawa et al. (2013). For another sludge at TS around 21.5\%, Charlou (2014) reported a fracturing phenomenon in a horizontal plane using a parallel plate rheometer in oscillation mode. The shearing test was inadequate to characterize this sludge. However, Battistoni (1997) succeeded in investigating the rheological properties of highly concentrated sludge (up to TS=33\%) with a coaxial cylindrical geometry. But, prior to the rheological test, the sludge was sieved (with a No. 20 U.S. standard sieve of $0.841 \mathrm{~mm}$ ) and sheared at a shearing rate of $100 \mathrm{~s}^{-1}$ for 4 minutes. These pretreatments not only irreversibly altered the composition, but also the microstructure of the sludge and the moisture distribution (Liang et al., 2016). It therefore seems that rotational rheometers have limited interest when working with a mechanically dewatered sludge. 
Alternative methods are reported in the literature. Ruiz and Wisniewski (2008) and Ruiz et al. (2010) adopted the Atterberg Limits, widely applied in civil engineering, to correlate the rheological characteristics of the sludge to its drying and shrinkage aptitudes. O'Kelly $(2005 ; 2006)$ applied triaxial compression tests, commonly used in soil mechanics, to simulate the mechanical and geotechnical behaviors of solid sludge around TS $=55 \%$ for landfilling purposes. Unfortunately, these methods are not suitable for the purpose of determining the rheological properties of highly concentrated sludge. In another scientific area, G'sell and Jonas (1979) proposed a tensile testing at constant local true strain rate to determine the plastic behavior of solid polymers with True strainTrue stress curves. Ramírez-Wong et al. (1996) used the squeezing flow viscometry technique and the definition of true strain and true stress to evaluate the rheological properties of fresh corn masa while S. Sharma and Bhattacharya (2014) adopted this method to show the fracture characteristics of model food gels. These studies share the common features of involving pasty, gelatinous or solid-like materials and compressing it between two parallel plates to provide an accurate measure of the material behavior during the test. Suitable for application in different fields, universal testing machines (UTM), also know as material testing machines, can perform many standard tests, including single and multiple cycle compression, tensile strength, creep, stress relaxation, resiliency, to describe the deformation behavior and creep properties of materials. UTM have also been marketed to specific sectors with specialized name (texture analyzer for food and top load compression tester for packaging, for instance). Thus, by referring to conventional uniaxial compression tests used for characterizing somewhat similar materials in various fields of research, such as single sludge granules (Lin et al., 2013), gels (Sharma and Bhattacharya, 2014; Yu et al., 2012), sandstones (Zhang et al., 2014) and asphalt mixtures (Cai et al., 2013), we developed an entire methodology - from experiment to modelling till simulation - to describe the deformation and flow of a mechanically dewatered sewage sludge (i.e. at TS around 20\%) under a given mechanical load.

For the characterization of sludge stickiness, Peeters et al. (2010) and Li et al. (2014) adapted the shearing test used in powder engineering to map the adhesive and cohesive stresses of sludge at increasing solid content. However, these tests only provided sticky strength under shearing. The other textural properties as strain energy density, resilience, energy of adhesion and cohesiveness for energy consumption analysis stayed unknown. The lack of these primary elements led us to adopt the entire analysis of texture, also using uniaxial cyclic compression test, developed in food engineering (Steffe, 1996; Hort et al., 1997) for better understanding of sludge behavior.

The present paper focuses on the experimental methodology only. The objective is first to analyze the rheological and textural behavior of the material, such as elasticity, viscosity, plasticity, hardening index and adhesive and cohesive parameters, under different types operational conditions. In a second part, particular emphasis is being placed on the reliability and sensitivity of this method that are justified by highlighting the changes induced by aging and mixing. This methodology is realised under uniaxial compression, so that it can be applied to sludge behaving as a soft solid with TS between the liquid limit (evaluated by slump test and/or ASTM D 4318 to ensure that the sludge sample can not flow with its own weight under gravity) and the plastic limit (ASTM D 4318 to ensure that it can be considered as a continuous medium).

\section{Material and method}

\subsection{Origin of the sewage sludge}

The sewage sludge was collected at the WWTP of Albi city in France. Before the biological treatment, the wastewater is screened, de-sanded and de-oiled (Figure 1). After the extended aeration, a posttreatment removes the nitrogen and the phosphorus from the effluent. The excess sludge is flocculated with a high cationic polymer (BASF Zetag ${ }^{\circledR} 8868$ ), thickened and anaerobically digested for six weeks. The digested sludge is flocculated again with a second high cationic polymer (BASF Zetag ${ }^{\circledR}$ 9018) and mechanically dewatered in centrifuges. The material used in this study was 
sampled after the centrifugation. Sludge composition was analyzed according to standard EN 12880:2000. The sample ranged in dry matter content from 18.5 to $21 \mathrm{wt} \%$.

As the sludge contains active organic matter, it is necessary to avoid biodegradation phenomena (aging) to have a chance of getting repeatable tests. Storing the sludge in a sealed barrel avoids water evaporation only. O'Kelly (2008) characterized the composition of a sludge sample kept at atmospheric conditions in a sealed barrel for 13 years: the TS only increased from $12 \%$ to $13 \%$ while the total volatile solids significantly decreased from $70 \%$ to $55 \%$. To block the biological activity, F. Chaari et al. (2003) added chemical reagents into the sludge and kept it in a fridge. Ma et al. (2014) refrigerated sludge at $4^{\circ} \mathrm{C}$ for one night. Nevertheless, by surveying the composition changes in extracellular polymeric substances, Nielsen et al. (1996) proved that the sludge biodegradation was mostly active during the first three days of storage and tended to be stable beyond 12 days. So, Curvers et al. (2009) stored the sludge at $4^{\circ} \mathrm{C}$ for 14 days, while Baudez et al. $(2013 ; 2011)$ have chosen a refrigerating storage of 30 days before testing. In this study, the sludge was immediately transported to the laboratory within one hour after sampling and divided into two samples. To prevent any aging effect, one was prepared immediately for testing while the second one was kept at $4^{\circ} \mathrm{C}$ for 6 days to investigate the influence of aging.

146

147

148

149

150

151

152

153

154

155

156

157

158

159

160

161

162

163

164

165

166

167

168

169

170

171

\subsection{Sample preparation}

Inherently, the sludge is an extremely heterogeneous material, whatever the observation scales. To be representative, a large sample is thus required. Furthermore, shaping the material into cylinder is needed for the test purpose. To have a chance to get a repeatable and reproducible protocol, three methods of preparation are tested and compared: (i) use of a cookie-cutter for shaping the raw sludge, (ii) manual extrusion of the raw sample and (iii) homogenization of the raw sludge with an automatic planetary mixer prior to the manual extrusion. The cylindrical cookie-cutter is pressed into the pasty sludge and then retrieved with a pre-formed piece of sludge. The manual piston extruder (Figure $\mathbf{2}$ (a)) is made up of a rack connected to a piston, a pinion connected to a crank (by which the torque is converted into a linear force on the piston while meshing the rack with the pinion), and a cylindrical recipient (13 cm in diameter). The sludge is pressed through a subconical tube, $3.4 \mathrm{~cm}$ in diameter, by the linear force. The extrusion can slightly homogenize a mass of sludge without changing its microstructure much. However, preshearing is widely used before testing in flowable sewage sludge rheological characterization on a conventional rheometer (Dai et al., 2014; Battistoni, 1997; Baudez et al., 2011; Markis et al. 2014). The aim is first to homogenize the sample, which is all the more critical than its volume is small (around $0.4 \mathrm{~mL}$ ), but also to erase the material memory. As the size of our samples is quite large (around $46 \mathrm{~mL}$ ), an automatic planetary mixer (Dito Sama, Sensils, France) is used to smash the polymer blobs and homogenize the original material.

\section{Figure 2}

A typical photo of the material after mixing and extrusion is shown on Figure $\mathbf{2}$ (c). Compared to the raw material (Figure $\mathbf{2}(\mathbf{b})$ ), its physical appearance is very different, smoother and shinier.

For each preparation method, the size and the weight of at least three cylindrical sludge samples is measured and the bulk density deduced. Neither significant loss in mass, nor remarkable gain in TS (about $0.2 \%$ ) was observed after premixing. Assessment of the sample homogeneity after shaping is based on the calculation of the standard deviation of the bulk densities. The average densities and the associated standard deviations are listed in the Table 1 for the three preparation methods.

\begin{tabular}{|c|c|c|c|}
\hline $\begin{array}{c}\text { Preparation } \\
\text { method }\end{array}$ & $\begin{array}{c}\text { Bulk density average } \\
\left(\mathrm{kg} / \mathrm{m}^{3}\right)\end{array}$ & $\begin{array}{c}\text { Standard deviation } \\
\left(\mathrm{kg} / \mathrm{m}^{3}\right)\end{array}$ & $\begin{array}{c}\text { Deviation percentage } \\
(\%)\end{array}$ \\
\hline Cookie cutter & 948.5 & 34.7 & 3.7 \\
\hline
\end{tabular}




\begin{tabular}{|c|l|l|l|}
\hline Extruder & 1061.8 & 13.9 & 1.3 \\
\hline Mixer \& extruder & 1046.5 & 12.7 & 1.2 \\
\hline
\end{tabular}

Table 1: Influence of sample preparation methods on averaged bulk density and standard deviation

The bulk density of samples shaped by cookie cutter is lower than that of water, because the incorporation of air within the loosened sludge. Extrusion reduces the material porosity and leads to denser samples. In addition, the extruded samples are more homogeneous than those made by using a simple cookie cutter. Premixing (10 min at about $1232 \mathrm{rpm}$ ) strengthens these trends. However, direct observation highlights that the premixed sludge is actually much more sticky than the original material. This phenomenon was also observed by Charlou (2014). To expect a repeatable and reproducible characterization method, extrusion is selected as the best method for preparing solidlike sludge samples. All the extruded sludge samples have the same dimensions, $r_{0}=17 \mathrm{~mm}$ and $h_{0}=$ $51 \mathrm{~mm}$, so the aspect ratio is $2 r_{0} / h_{0}=1.5$. Aging and premixing are considered as two operating parameters, whose influence has to be tested. Further more, as the sludge is extruded into cylinders, the sludge on the surface of the shaped cylindrical samples is somewhat sheared, pressed or squeezed. The premixing test is thus indispensable to verify whether the sample shaping by extrusion is reliable and applicable or not.

All the experiments are carried out in the air-conditioned laboratory $\left(21^{\circ} \mathrm{C}\right)$. The TS of sludge is surveyed before sample preparation and after compression test in order to verify that the water evaporation is negligible and has no impact of the measurement.

\subsection{Uniaxial compression at different velocities or deformations}

All the mechanical tests described in the following are carried out with the material testing machine (UTM) LRX Plus of Lloyd Instrument (Elancourt, France) with capacity up to $5 \mathrm{kN}$. The UTM (Figure 3) includes a control console, a fixed worktable, a single column with a crosshead travel range of $735 \mathrm{~mm}$ embedded with an interchangeable mobile load cell equipped with a force sensor of $50 \mathrm{~N}$. The uniaxial compression tests are configured at a constant crosshead displacement speed V $(\mathrm{mm} / \mathrm{s})$, either with a maximal loading force $F_{\max }(N)$ or a maximal sample change in height $\Delta h_{\max }(m m)$. During the experiment, the force $F(N)$, the time $t(s)$, and the crosshead displacement (namely the change in height of the sludge sample) $\Delta \mathrm{h}(\mathrm{mm})$, are recorded on a computer.

\section{Figure 3}

Three different types of mechanical tests were performed:

- Single compression tests on fresh raw sludge samples with $\Delta \mathrm{h}_{\max }=35 \mathrm{~mm}$ and $\mathrm{V}=0.5 \mathrm{~mm} / \mathrm{s}$, to define the bioyield point which is related to a failure in the microstructure of the material and also known as the fracturability (Pelletier et al., 1998; Mohsenin, 1984);

- 1 cycle (loading-unloading) compression tests on fresh raw sludge samples with different maximal deformations $\left(\Delta \mathrm{h}_{\max }=1,2,3\right.$ and $\left.10 \mathrm{~mm}\right)$ at fixed compression speed $\mathrm{V}=0.5 \mathrm{~mm} / \mathrm{s}$ the upstroke phase occurs once the crosshead reaches the preset $\Delta \mathrm{h}_{\max }$ - to identify the rheological behavior of the material under 1 cycle of loading and releasing manipulations;

- 2 consecutive cycles (loading-unloading) compression tests on three types of samples (fresh raw, fresh destructured and aging raw) with different compression speeds $(V=0.5,1.0$ and $1.5 \mathrm{~mm} / \mathrm{s}$ ) at fixed maximal deformation $\Delta \mathrm{h}_{\max }=10 \mathrm{~mm}$ to determine the rheological behavior and textural properties of the material under 2 cycles of loading and releasing manipulations (Pelletier et al., 1998).

For each input condition at least three samples are characterized. 


\subsection{True stress and true strain}

A typical force measured in response to a cyclic mechanical compression test with pre-set maximal deformation (here $\Delta \mathrm{h}_{\max }=35 \mathrm{~mm}$ ) and crosshead displacement speed (here $\mathrm{V}=0.5 \mathrm{~mm} / \mathrm{s}$ ) is plotted over time in Figure 4.

Figure 4

In order to interpret the rheological behavior of the sludge sample, the true stress $\sigma(\mathrm{Pa})$, and the true strain $\varepsilon(-)$, are computed from the instantaneous force $F$, the cross-sectional area $S\left(\mathrm{~m}^{2}\right)$, and the deformation $\Delta \mathrm{h}$. We assume (i) that there is no friction at the contact surface between the sample and the UTM plates (ii) that the cylindrical sludge sample is incompressible (The bulk volume of cylindrical samples measured before and after compression test is almost unchanged.). So the samples can keep their cylindrical shape during the compression tests. Of course, the side surface of the sample is slightly curved after the compression test. However, the ratio of diameters between the sections of higher and lower radii is about 1.07, and the discrepancy between the original size and the final one is less than $10 \%$, as can be seen on Figure 6 , thus this assumption seems quite acceptable.

Since the extruded cylindrical sample is considered incompressible during a trial, the instantaneous cross-sectional area $\mathrm{S}(\mathrm{t})$ can be calculated according to the conservation of the sample's volume:

$$
\mathrm{S}(\mathrm{t})=\pi \mathrm{r}(\mathrm{t})^{2}=\frac{\mathrm{h}_{0}}{\left(\mathrm{~h}_{0}-\Delta \mathrm{h}(\mathrm{t})\right)} \pi \mathrm{r}_{0}^{2}
$$

231

Where $r(t)$ is the sample's radius at time $t$.

The previous assumption of sliding without friction during uniaxial compression leads to a uniform and uniaxial stress field. The true stress $\sigma$ is thus expressed as the force $F(t)$ divided by the instantaneous cross-sectional area $\mathrm{S}(\mathrm{t})$ :

$$
\sigma(\mathrm{t})=\frac{\mathrm{F}(\mathrm{t})}{\mathrm{S}(\mathrm{t})}=\frac{\left(\mathrm{h}_{0}-\Delta \mathrm{h}(\mathrm{t})\right)}{\mathrm{h}_{0}} \cdot \frac{\mathrm{F}(\mathrm{t})}{\pi \mathrm{r}_{0}^{2}}
$$

The axial true strain increment $d \varepsilon$ is defined as the height increment dh divided by the instantaneous height $h(t): d \varepsilon=\frac{d h}{h(t)}$. Therefore, the axial true strain $\varepsilon(t)$ is calculated as follows:

$$
\varepsilon(\mathrm{t})=\ln \left(\frac{\mathrm{h}_{0}+\Delta \mathrm{h}(\mathrm{t})}{\mathrm{h}_{0}}\right)
$$

In the following, all the experimental data are converted into true stress and true strain (often called stress and strain for short).

\subsection{Strain energy density and resilience}

It is assumed that there is no friction on contact surfaces, so it is considered that there is no energy dissipated by friction in these tests. The energy introduced into the material due to the loading is therefore assimilated to the strain energy. The strain-energy density of the material $\mathrm{u}\left(\mathrm{J} / \mathrm{m}^{3}\right)$ corresponds to the normalized strain energy by unit volume that is needed to achieve a certain deformation. It is equal to the area under the stress-strain diagram:

$$
\mathrm{u}=\int_{\text {loading }} \sigma \mathrm{d} \varepsilon
$$


If the material is not perfectly elastic, only part of the strain energy can be recovered after the load is removed. The recoverable part is the resilience of the material $u_{r}$ (Roudot, 2002). $u_{r}$ is equal to the area of the stress-strain curve during unloading:

$$
\mathrm{u}_{\mathrm{r}}=\int_{\text {unloading }} \sigma \mathrm{d} \varepsilon
$$

Where $u_{r}$ is also expressed in $\mathrm{J} / \mathrm{m}^{3}$.

Finally, the difference $u-u_{r}$ gives the energy density that is irreversibly stored or dissipated within the sample, as permanent deformation, heat or cracking, during a loading-unloading application. A ratio between unrecoverable energy and strain energy, e (\%), can be obtained as follows:

$$
\mathrm{e}=\frac{\mathrm{u}-\mathrm{u}_{\mathrm{r}}}{\mathrm{u}}
$$

\subsection{Texture profile analysis}

In food science, double compression tests are recognized as an instrumental means of characterizing the texture of the material (Steffe, 1996). Usually, the sample is compressed two times, up to $80 \%$ of its original height, with the UTM. Several textural parameters can be deduced from the texture profile curve. This curve represents the evolution of the force over the time. Three of them are of particular interest for sludge treatment - adhesive strength, energy of adhesion and cohesiveness since the adhesion to the filter clothes during mechanical dewatering, to the dryer walls during thermal drying or to the chopping blades of stirring device in solar dryers is very common in sludge treatment. A product with strong cohesion will be more tolerant of manufacturing.

The adhesive strength $F_{a d, m a x}$ is the maximum negative force. Knowing the contact surface, the adhesive stress $\sigma_{a d, \max }$ can be calculated. The energy of adhesion $w_{\text {ad }}$ represents the mechanical work caused by a tensile force to separate the material from the plate. $\mathrm{W}_{\mathrm{ad}}$, expressed in J, corresponds to the area under the zero force line after the compression:

$$
\mathrm{w}_{\mathrm{ad}}=\int_{\text {adhesion }} \mathrm{FVdt}
$$

Where $F$ is the adhesive force measured between the two cycles and $V d t$ is the displacement increment. The values of adhesive strength and the energy of adhesion are negative, absolute numbers will be reported in Table 2 to 5 .

The cohesiveness co, a dimensionless quantity, corresponds to the ratio of the mechanical work done by the compression force during the second compression $w_{2}$ to the mechanical work done by this force during the first compression $w_{1}$. The cohesiveness is used to evaluate how well the material withstands a second deformation relative to its resistance under the first deformation. It is calculated as follows:

$$
\text { co }=\mathrm{w}_{2} / \mathrm{w}_{1} \text { with } \mathrm{w}_{\mathrm{k}}=\int_{\mathrm{k}^{\text {th }}} \text { cycle } \mathrm{FVdt}
$$

Where $k$ is the $k^{\text {th }}$ compression cycle.

\section{$4 \quad$ Results and discussion}

\subsection{Identification of rheological and textural properties}

The TS of tested sludge samples are $18.86 \%$ before shaping preparation and $19.37 \%$ after compression test. This increase of $0.5 \%$ in TS due to water evaporation is negligible. The experimental results are therefore reliable for sludge behavior interpretation. 


\subsubsection{Identification of the bioyield point through simple compression}

The mechanical responses of three sludge samples, directly shaped into cylinder by extrusion, to a single loading phase are plotted in Figure $\mathbf{5}(\mathbf{a})$ (b). The experiment was performed at $V=0.5 \mathrm{~mm} / \mathrm{s}$ with $\Delta \mathrm{h}_{\max }=35 \mathrm{~mm}$. Results are very well repeatable with a clear trend. A curve such as the one illustrated in Figure $\mathbf{5}$ (a) (b) is typical for solid foods, biological solids (Steffe, 1996) but also for solid polymer (G'sell and Jonas, 1979). The flocculation of municipal sewage sludge particles is a decisive step in sludge processing. The high cationic polymer forms the sludge structure with a good mechanical strength (Agoda-Tandjawa et al., 2013; Wolny et al., 2008). This may be one of the essential reasons that explain the similarity of the rheological behavior of these materials.

\section{Figure 5}

Except near the origin $(\varepsilon<0.015)$ where the curve is concave, the initial part of the curve is almost a straight line up to the limit of linearity (around $\varepsilon=0.05$ ). The concavity may result from three reasons: the non-parallelism of contact surfaces, which is a default of sludge samples; the rearrangement of the skeleton (some kind of collapse) owing to the applied stress; and the sludge adhesion to the contact surface of load cell. These phenomena are very common. For instance, Johnson et al. (1971) pointed out the significance of attractive surface under light load with soft materials. Sharma et al. (2011) also observed it when compressing human and animal lenses. Consequently, the data in this concave range will not be exploited for further behavior analysis.

The apparent elastic modulus, slope of stress-strain curve in the linear range $(0.015<\varepsilon<0.05)$, is often considered as an index of firmness. For these specific conditions, the estimated value is $78.2 \pm 9.0 \mathrm{kPa}$. This order of magnitude is quite close to the elastic modulus of gelatin gel, of some rubber or banana (Chhabra and Richardson, 2011) and that of concentrated premixed sludge (TS $\approx 17.4 \%$ ) (Ségalen et al., 2015). For $\varepsilon>0.05$, the stress continues to increase with the progress of loading, however, the slope starts to decrease, which indicates the deferred behavior of viscoelastic property.

The stress reaches the maximum value around $\sigma_{\mathrm{c}}=7300 \mathrm{~Pa}$ at $\varepsilon_{\mathrm{c}}=0.21$. This maximum, called the bioyield point, reflects the sensitivity of the biomaterial to irreversible internal damage. Beyond this point, the stress decreases with increasing strain. The machine actually measures the propagation of micro-fractures. The data can no longer provide direct access to the intrinsic properties of sludge samples. Therefore, the strain range will be limited to 0-0.21 in the following cyclic compressions.

During the mechanical tests, only external fissures or fractures can be seen. In order to ensure that there is no internal fissures or fractures, after the test, free of external cracks samples are cut into slices. Only the samples without evident cracking are kept for further data analysis (Figure 6).

\section{Figure 6}

\subsubsection{Identification of the rheological behavior through cyclic compressions}

The stress-strain curves for a loading-unloading cycle with maximum deformations $\Delta \mathrm{h}_{\max }=1,2,3$ and $10 \mathrm{~mm}$ and $V=0.5 \mathrm{~mm} / \mathrm{s}$ are plotted in Figure $\mathbf{5}$ (c). In the loading phase, the curves are well superposed, in the unloading phase, the curves for $\Delta \mathrm{h}_{\max }=1$ and $2 \mathrm{~mm}$ display very rapid recovery at the end parts in comparison with those for $\Delta \mathrm{h}_{\max }=3$ and $10 \mathrm{~mm}$. It might be inferred that there is a change of regime between the maximum stress values of $\Delta \mathrm{h}_{\max }=2$ and $3 \mathrm{~mm}$, namely between 2300 and $4100 \mathrm{~Pa}$.

When the compression starts, the concavity of the loading curves is observed again in the range up to about $\varepsilon_{\mathrm{A}}=0.01$ and $\sigma_{\mathrm{c}}=7300 \mathrm{~Pa}$. 
For $\Delta \mathrm{h}_{\max }=1 \mathrm{~mm}$, a half of the data in loading phase is within this range. So only the data in the unloading phase are effective for behavior analysis. As can be seen on Figure $\mathbf{5}$ (c), the slope of stress-strain curve decreases, this means that the recovery speed of the material increases. Plus, the sludge can almost completely recover itself. Hence, sludge samples exhibit a viscoelastic behavior at small deformation. As the relaxation time of this viscoelastic body, defined as the ratio of its viscosity to its elastic modulus, is the same order of magnitude as the unloading time in this test ( $2 \mathrm{~s})$, we can then estimate that the order of magnitude for the sludge viscosity is $10^{4}$ to $10^{5} \mathrm{~Pa}$.s. This value is very close to the viscosity of borosilicate glass at $900{ }^{\circ} \mathrm{C}$ (Dusserre et al., 2011).

For $\Delta \mathrm{h}_{\max }=2 \mathrm{~mm}$, a quarter of data in the loading phase is influenced by the curve concavity. Accordingly, the data in the unloading phase are main reference for analysis. A small residual deformation of $0.87 \mathrm{~mm}(\varepsilon=0.0169)$ is measured. However, as this value is in the concave range of $\varepsilon<0.01$, it is hard to define whether this residual deformation is generated by plastic property or if it is just the initial distance between the contact surfaces of the material and the load cell. Thus, it is still the viscoelastic property that dominates the sludge behavior in this test.

For $\Delta \mathrm{h}_{\max }=3$ and $10 \mathrm{~mm}$, the hysteretic behavior between loading and unloading curves become more evident. The residual deformations are $1.13 \mathrm{~mm}(\varepsilon=0.0219)$ and $6.04 \mathrm{~mm}(\varepsilon=0.119)$, respectively. The strains are out of the range of the concavity, so these irreversible deformations should be the plastic effect of sludge samples. This confirms that the yield stress is exceeded in the test for $\Delta \mathrm{h}_{\max }=3 \mathrm{~mm}$. Above the threshold, the change of regime takes place, the material undergoes plastic deformations and the slope of stress-strain curves decreases much more significantly with the downstroke. For $\Delta \mathrm{h}_{\max }=10 \mathrm{~mm}$, by the end of loading phase $(0.19<\varepsilon<0.21)$, the stress varies very little (from 6477 to $6542 \mathrm{~Pa}$ ), the sludge's behavior is very similar to a plastic flow. The sludge sample behaves like a viscoelastic body, again, in unloading phase.

The previous four tests are carried out with fixed crosshead displacement speed $V=0.5 \mathrm{~mm} / \mathrm{s}$ and different maximal deformations $\Delta \mathrm{h}_{\max }$; in the following characterizing measurements, $\Delta \mathrm{h}_{\max }$ is fixed to $10 \mathrm{~mm}$ with $\mathrm{V}$ preset at $0.5,1.0$ and $1.5 \mathrm{~mm} / \mathrm{s}$. The stress-strain curves for two loading-unloading cycles are plotted in Figure $\mathbf{5}$ (d).

At the beginning of the compression, the concavity of curves persists. For $0.01<\varepsilon<0.03$, the material response is nearly rate-independent. In this strain range, the effect of viscoelasticity is not yet notable, plus the elastic behavior is independent of compression speed, so the curves are almost linear in this part. The elastic property prevails until $\varepsilon_{\mathrm{E}}=0.03$ and $\sigma_{\mathrm{E}}=2000 \mathrm{~Pa}$. The impact of crosshead displacement speed $\mathrm{V}$ becomes remarkable with growing influence of viscoelasticity effect: to achieve the same deformation $\varepsilon=0.01$, it requires higher stress for higher compression speed test: $6403 \mathrm{~Pa}$ (13\% higher) for $\mathrm{V}=1.5 \mathrm{~mm} / \mathrm{s} ; 5896 \mathrm{~Pa}$ (4\% higher) for $\mathrm{V}=1.0 \mathrm{~mm} / \mathrm{s}$ in comparison with $5667 \mathrm{~Pa}$ for $\mathrm{V}=0.5 \mathrm{~mm} / \mathrm{s}$. This increase in stress with the augmentation of compression speed confirms the existence of viscous property in sludge samples.

According to the Newton's law, the stress is proportional to the strain rate when the viscosity is constant, however, at $\varepsilon=0.1$, the strain rates are $0.0326 \mathrm{~s}^{-1}, 0.0217 \mathrm{~s}^{-1}$ and $0.0109 \mathrm{~s}^{-1}$, respectively. The corresponding stress value is not in proportion with the increase of strain rates. The sludge samples exhibit therefore a shear thinning property as widely reported (Jiang et al., 2014; Mori et al., 2008; Ma et al., 2014; Markis et al., 2014).

To estimate the order of magnitude of the yield stress (see Figure $\mathbf{5}$ (d)), two regression lines are plotted: one is regressed with the data in the range $0.01<\varepsilon<0.03$, this line simulates the ideal elastic behavior of the material; the other is regressed with the data by the end of loading $0.19<\varepsilon<0.21$, to simulate the ideal plastic behavior of the material. The intersection of these two lines corresponds to the critical strain around $\varepsilon_{\mathrm{c}}=0.08$, the yield stress is therefore estimated to be around $4600 \mathrm{~Pa}$ for 
$\mathrm{V}=0.5 \mathrm{~mm} / \mathrm{s}, 4950 \mathrm{~Pa}$ for $\mathrm{V}=1.0 \mathrm{~mm} / \mathrm{s}$ and $5700 \mathrm{~Pa}$ for $\mathrm{V}=1.5 \mathrm{~mm} / \mathrm{s}$. Not only the viscosity, but also the yield stress is very dependent on the compression speed. Above this critical yield stress, the sludge goes through large deformations including elastic, viscous and plastic ones. The sludge samples behave as a visco-elasto-plastic body to the end of loading phase.

Once the crosshead displacement has reached the pre-set maximal deformation, the discharging phase starts. At the end of the discharging process, the strain is non-zero when the stress reaches zero. Thus, as expected following the charging cycle analysis, two types of deformations can be identified:

- A recoverable deformation, which might be induced either by the elasticity or the viscoelasticity of the sludge. The discharging curves show pure elastic response at the very beginning of the unloading phase (Sveegaard et al., 2012). But rapidly, the predominance of the viscoelastic recovery behavior of sludge appears, since an elastic material should have recovered itself linearly all along the discharging phase in accordance with the Hooke's law;

- And a permanent deformation mostly caused by its plastic property. This permanent deformation does not depend on the crosshead speed, as can be seen on Figure $\mathbf{5}$ (d). The higher the viscosity, the longer the relaxation time needed for the material to recover itself. According to the experiment duration, the so-called permanent deformation is around $5.3 \mathrm{~mm}(\varepsilon=0.11)$.

Most of the viscoplastic deformation occurs during the first compression cycle and, if the material is loaded again, viscoelastic deformations prevail then. The concavity of the curve near the origin is clearly less marked. This highlights that the hardening during the first cycle is enough to protect the sludge sample from new irreversible (plastic) deformations.

\subsubsection{Influence of the operating conditions on the resilience and textural properties}

Energy input and output values as well as textural properties are reported in Table 2. With the augmentation of compression speed, the maximum density of strain energy and the maximum adhesive stress increase. But the resilience, the energy of adhesion and the cohesiveness of sludge samples remain the same.

\begin{tabular}{|c|c|c|c|c|c|}
\hline $\mathrm{V}(\mathrm{mm} / \mathrm{s})$ & $\mathrm{u}\left(\mathrm{J} / \mathrm{m}^{3}\right)$ & $\mathrm{e}(-)$ & $\sigma_{\mathrm{ad}, \max }(\mathrm{Pa})$ & $\mathrm{w}_{\mathrm{ad}}\left(10^{-6} \mathrm{~J}\right)$ & $\mathrm{co}(-)$ \\
\hline 0.5 & $1055 \pm 86$ & $75.3 \pm 1.2 \%$ & $195 \pm 63$ & $88.5 \pm 5.9$ & $47.5 \pm 1.9 \%$ \\
\hline 1.0 & $1099 \pm 28$ & $75.3 \pm 0.8 \%$ & $242 \pm 50$ & $85.4 \pm 29.3$ & $48.2 \pm 1.0 \%$ \\
\hline 1.5 & $1177 \pm 38$ & $75.4 \pm 1.0 \%$ & $310 \pm 37$ & $119.0 \pm 8.4$ & $47.7 \pm 1.3 \%$ \\
\hline
\end{tabular}

Table 2: Calculated textural properties of sludge tested at increasing compression speed

\subsection{Sensitivity of the method to highlight structural changes in the material}

After mechanical dewatering, shearing and storing the sludge are almost unavoidable. It is wellknown that both events have influences on the flow properties of the sludge (Kudra, 2003; Yen et al., 2002). They also have influences on its stickiness. Indeed, Charlou (2014) emphasized that a simple kneading makes the sludge sample significantly more adhesive than the raw one, without any change in solid content, temperature or composition. Both the microstructure (Charlou, 2014), characterized through the measurement of the particle size distribution, and the moisture distribution, measured by using low field ${ }^{1} \mathrm{H}$ nuclear magnetic resonance test, are modified (Liang et al., 2016). The final section of this paper examines the ability of this method to reveal changes in rheological properties induced by structural changes in the material.

\subsubsection{Influence of aging}

The stress- strain plots of three fresh sludge samples and three aged sludge samples (stored during 6 days in a cold room at $4^{\circ} \mathrm{C}$ ) are plotted in Figure 7. 
417

418

419

420

421

422

423

424

425

426

427

428

429

430

431

432

433

434

435

436

437

438

439

440

441

442

443

444

445

446

447

448

449

450

451

452

453

Aging does not have any significant effect on the apparent Young's modulus. On the contrary, all the other rheological properties are very sensitive to the changes induced by the storage. The threshold stress corresponding to the limit between the viscoelastic and the viscoplastic domains decreases with aging. The raw sludge exhibits a viscoelastic behavior up to around $\sigma_{p}=4600 \mathrm{~Pa}$ while this threshold stress is around $\varepsilon_{\mathrm{p}}=0.05$ and $\sigma_{\mathrm{p}}=3670 \mathrm{~Pa}$ (about $20.2 \%$ lower) for the aged samples. At the end of the charging process, the maximum true stress is $6.4 \%$ lower for the aged samples. And finally, the permanent deformation is about $22.4 \%$ greater for the aged samples. From an energy point of view (see Table 3 ), the strain energy density $u$ decreases with aging while the ratio e increases. As a result, the absolute total amount of energy dissipated within the material u•e is independent of aging. However, aging has a great influence on the textural properties of the material: the adhesive stress is doubled, the energy of adhesion increases more than 30 times and the sludge cohesiveness is reduced by $38.8 \%$, emphasizing structural changes both at micro and macro scales.

\begin{tabular}{|c|c|c|c|c|c|}
\hline Aging (day) & $\mathrm{u}\left(\mathrm{J} / \mathrm{m}^{3}\right)$ & $\mathrm{e}(-)$ & $\sigma_{\mathrm{ad}, \max }(\mathrm{Pa})$ & $\mathrm{w}_{\mathrm{ad}}\left(10^{-6} \mathrm{~J}\right)$ & $\mathrm{co}(-)$ \\
\hline 0 & $1055 \pm 86$ & $75.3 \pm 1.2 \%$ & $217 \pm 31$ & $88.5 \pm 5.9$ & $63.9 \pm 0.9 \%$ \\
\hline 6 & $991 \pm 40$ & $80.7 \pm 0.9 \%$ & $475 \pm 52$ & $2878.6 \pm 331.5$ & $39.1 \pm 1.4 \%$ \\
\hline
\end{tabular}

Table 3: Calculatd textural properties of fresh and aged sludge samples

\subsubsection{Influence of mixing}

Before the mechanical test, two portions of sludge have been mixed for 5 and $20 \mathrm{~min}$, respectively, at about $1232 \mathrm{rpm}$. The 5 minutes' mixing is designed to reveal the impact of light destruction on sludge behavior with respect to the intense mixing for 20 minutes. The stress- strain plots of the raw sludge and the premixed samples are presented in Figure 8.

\section{Figure 8}

Mixing has nearly the same influence on the rheological properties as aging. The intense mixing (20 $\mathrm{min}$ ) has more important impact on sludge behavior than light mixing at $5 \mathrm{~min}$. The sample shaping by extrusion causes simply very slight destruction on the surface of sludge cylinders, especially in comparison with 5 minutes mixing at $1232 \mathrm{rpm}$, it can thus be deduced that the extrusion barely modify sludge properties. The extruded samples still represent very well the original sludge.

With respect to the original sludge sample behavior, the apparent elastic modulus the intensely mixed sludge sample is unchanged. The threshold stress corresponding to the limit between the viscoelastic and the viscoplastic domains decreases from $4509 \mathrm{~Pa}$ to $3381 \mathrm{~Pa}$ (about $25.0 \%$ lower) while the permanent deformation is $7.2 \%$ higher, and, as expected, the maximum true stress measured at the end of the charging cycle is reduced by $22.7 \%$. Mixing breaks the long polymeric chains (Charlou, 2014), therefore, a lower stress is required to get the same deformation in comparison to the original non-mixed sludge samples. From an energy point of view (see Table 4), the strain energy density $u$ decreases with mixing while the ratio e increases. All in all, the absolute total amount of energy dissipated within the material is $17 \%$ lower for the mixed sample. Regarding the textural properties, mixing does not change the sludge cohesiveness, contrary to aging. This suggests that cohesiveness arises mainly from physical and chemical bonds at the floc's scale. On the other hand, mixing increases significantly the adhesive stress and the energy of adhesion the material.

\begin{tabular}{|c|c|c|c|c|c|}
\hline Mixing $(\mathrm{min})$ & $\mathrm{u}\left(\mathrm{J} / \mathrm{m}^{3}\right)$ & $\mathrm{e}(-)$ & $\sigma_{\mathrm{ad}, \max }(\mathrm{Pa})$ & $\mathrm{w}_{\mathrm{ad}}\left(10^{-6} \mathrm{~J}\right)$ & $\mathrm{co}(-)$ \\
\hline 0 & $1199 \pm 40$ & $81.5 \pm 0.4 \%$ & $248 \pm 28$ & $122.1 \pm 15.4$ & $39.33 \pm 0.4 \%$ \\
\hline 5 & $1163 \pm 60$ & $82.4 \pm 1.0 \%$ & $8743 \pm 23$ & $1007.7 \pm 419.8$ & $39.86 \pm 0.8 \%$ \\
\hline 20 & $964 \pm 54$ & $83.8 \pm 0.7 \%$ & $1264 \pm 132$ & $1618.8 \pm 324.5$ & $40.02 \pm 0.5 \%$ \\
\hline
\end{tabular}

Table 4: Calculated textural properties of original and premixed sludge 
In any case, the method is sensitive enough to reveal changes induced by structural changes in the material.

\section{Conclusion}

An entire protocol of uniaxial compression tests is developed to characterize the complex transition between solid and fluid states behavior of mechanically dewatered sewage sludge of TS $\approx 20 \%$. The sample preparation by extrusion reduces the sludge heterogeneity and ensures the good repeatability of mechanical tests. The single large strain (115\%) compression serves to identify the bioyield of the material; the sequential series of cyclic compressions are then limited up to the previously identified bioyield (strain<0.21) with various operating conditions: compression speeds, maximum deformations, destructured sludge and aged samples. With true stress-true strain plots, it is illustrated that the viscoelastic behavior of sludge samples below yield stress and the plastic deformations when exceeding the threshold. The rheological and textural properties of tested samples are determined, and the impacts of destructure and biodegradation on the sludge behavior is highlighted. This methodology revealed that the viscosity and the yield stress are the most sensible rheological factors to operational conditions. To improve the flow control in processing, the optimization handling should be focused on reducing these two factors. Aging and premixing can decrease the yield stress and the viscosity of sludge, however, they increase accordingly the adhesive effect of sludge. So, the characterization studies on the rheological and textural properties of sludge are essential in process optimization.

The uniaxial compression test is proved to be an effective and sensitive characterizing method with good repeatability and reproducibility. The identified rheological behaviors and the estimated properties' values will be used for the following modelling and numerical simulation parts of our characterization methodology. This methodology can be applied to characterize soft solid materials, which do not flow under their own weight by gravity (higher that liquid limit) and, at the same time, can be considered as continuous media (lower that plastic limit). 
Agoda-Tandjawa, G., Dieudé-Fauvel, E., Girault R., and Baudez J.C., 2013. "Using Water Activity Measurements to Evaluate Rheological Consistency and Structure Strength of Sludge." Chemical Engineering Journal 228: 799-805.

Baroutian, S., Eshtiaghi, N., and Gapes D.J., 2013. "Rheology of a Primary and Secondary Sewage Sludge Mixture: Dependency on Temperature and Solid Concentration." Bioresource Technology 140: 227-33.

Battistoni, P., 1997. "Pre-Treatment, Measurement Execution Procedure and Waste Characteristics in the Rheology of Sewage Sludges and the Digested Organic Fraction of Municipal Solid Wastes." Water Science and Technology, Sludge Rheology Selected Proceedings of the International Workshop on the Rheology of Sludges Sludge Management International Specialized Conference on Sludge Management, 36 (11): 33-41.

Baudez, J.C., 2008. "Physical Aging and Thixotropy in Sludge Rheology." Applied Rheology 18 (1): 13495.

Baudez, J.C., and Coussot, P., 2001. "Rheology of Aging, Concentrated, Polymeric Suspensions: Application to Pasty Sewage Sludges." The Society of Rheology 45 (5): 1123-39.

Baudez, J.C., Markis F., Eshtiaghi N., and Slatter P., 2011. "The Rheological Behaviour of Anaerobic Digested Sludge." Water Research 45 (17): 5675-80.

Baudez, J.C., Slatter P, and Eshtiaghi N., 2013. "The Impact of Temperature on the Rheological Behaviour of Anaerobic Digested Sludge." Chemical Engineering Journal 215-216 (January): 182-87.

Baudez, J.C., Coussot P., and Thirion F., 1998. "Rheology of sludge of Wastewater Treatment Plant: Preliminary studies for mastering of storage and spreading." (in French, Rhéologie Des Boues de Stations D'épuration : études Préliminaires Pour La Maîtrise Des Stockages et épandages.) Ingénieries - EAT - N 15.

Beckley, J. and Banerjee, S., 1999. "Operational issues with impulse drying sludge." Water Science \& Technology 40 (11-12): 163-168.

Cai, W., McDowell G. R., and Airey G. D., 2013. "Discrete Element Modelling of Uniaxial Constant Strain Rate Tests on Asphalt Mixtures." Granular Matter 15 (2): 163-74.

Chaari, F., Racineux G., Poitou R., and Chaouche M., 2003. "Rheological Behavior of Sewage Sludge and Strain-Induced Dewatering." Rheologica Acta 42 (3): 273-79.

Charlou, C., 2014. "Characterization and modelling of sewage sludge flow in paddle dryer" (in French, Caractérisation et modélisation de l'écoulement des boues résiduaires dans un sécheur à palettes.), PhD. Thesis, Albi: Université de Toulouse.

Chhabra, R. P., and Richardson J. F., 2011. Non-Newtonian Flow and Applied Rheology: Engineering Applications. Butterworth-Heinemann.

Coussot, P., 2014. "Yield Stress Fluid Flows: A Review of Experimental Data." Journal of NonNewtonian Fluid Mechanics 211 (September): 31-49.

Curvers, D., Saveyn H., Scales P. J., and Van der Meeren P., 2009. "A Centrifugation Method for the Assessment of Low Pressure Compressibility of Particulate Suspensions." Chemical Engineering Journal 148 (2-3): 405-13.

Dai, X., Gai X., and Dong B., 2014. "Rheology Evolution of Sludge through High-Solid Anaerobic Digestion." Bioresource Technology 174: 6-10.

Dusserre, G., Bernhart G., Schmidt F. M., and Dour G., 2011. "Evaluation of Viscous and Elastic Parameters of a Borosilicate Glass above Transition Temperature Using Optical Instrumented Squeeze Tests." Journal of Non-Newtonian Fluid Mechanics 166 (21-22): 1229-38.

Eshtiaghi, N., Markis F., Dong Yap S., Baudez J.C., and Slatter P., 2013. "Rheological Characterisation of Municipal Sludge: A Review." Water Research 47 (15): 5493-5510.

Farno, E., Baudez J.C., Parthasarathy R., and Eshtiaghi N., 2014. "Rheological Characterisation of Thermally-Treated Anaerobic Digested Sludge: Impact of Temperature and Thermal History." Water Research 56: 156-61. 
Feng, G., Liu L., and Tan W. 2014. "Effect of Thermal Hydrolysis on Rheological Behavior of Municipal Sludge." Industrial \& Engineering Chemistry Research 53 (27): 11185-92.

G'sell, C. and Jonas J. J., 1979. "Determination of the Plastic Behaviour of Solid Polymers at Constant True Strain Rate." Journal of Materials Science 14 (3): 583-91.

Hort, J., Grys, G., and Woodman, J., 1997. "The relationships between the chemical, rheological and textural properties of Cheddar cheese." Le lait 77 (5): 587-600.

Jiang, J., Wu J., Poncin S., and Li H., 2014. "Rheological Characteristics of Highly Concentrated Anaerobic Digested Sludge." Biochemical Engineering Journal 86: 57-61.

Jing, S.R., Lin, Y.F., Lin, Y.M., Hus, C.S., Huang, C.S., and Lee, D.Y., 1999. "Evaluation of effective conditioners for enhancing sludge dewatering and subsequent detachment from filter cloth." Journal of Environmental Science and Health Part A 34(7): 1517-1531.

Johnson, K. L., Kendall K., and Roberts A. D., 1971. "Surface Energy and the Contact of Elastic Solids." Proceedings of the Royal Society of London A: Mathematical, Physical and Engineering Sciences 324 (1558): 301-13.

Kudra, T., 2003. "Sticky Region in Drying-Definition and Identification." Drying Technology 21 (8): 1457-69.

Li, B., Wang, F., Chi, Y., and Yan. J.H., 2014. "Adhesion and Cohesion Characteristics of Sewage Sludge During Drying." Drying Technology 32 (13): 1598-1607.

Liang, F., Chen X., Mao H., Sauceau M., Arlabosse P., Wang F., and Chi Y., 2016. "The Microstructure: A Critical Factor In Characterising The Sticky Properties Of Highly Concentrated Sewage Sludge." 6th International Conference on Engineering for Waste and Biomass Valorisation.

Lin, Y. M., Sharma P. K., and van Loosdrecht M. C. M., 2013. "The Chemical and Mechanical Differences between Alginate-like Exopolysaccharides Isolated from Aerobic Flocculent Sludge and Aerobic Granular Sludge." Water Research 47 (1): 57-65.

Lotito, V., and Lotito A. M., 2014. "Rheological Measurements on Different Types of Sewage Sludge for Pumping Design." Journal of Environmental Management 137: 189-96.

Markis, F., Baudez J.C., Parthasarathy R., Slatter P., and Eshtiaghi N., 2014. "Rheological Characterisation of Primary and Secondary Sludge: Impact of Solids Concentration." Chemical Engineering Journal 253 (October): 526-37.

Ma, Y., Xia C., Yang H., and Zeng R. J., 2014. “A Rheological Approach to Analyze Aerobic Granular Sludge." Water Research 50 (March): 171-78.

Mohsenin, N. N., 1984. Physical Properties of Food and Agriculture Materials : A Teaching Manual. New York: Gordon and Breach Science Publishers.

Mori, M., Isaac J., Seyssiecq I., and Roche N., 2008. "Effect of Measuring Geometries and of Exocellular Polymeric Substances on the Rheological Behaviour of Sewage Sludge." Chemical Engineering Research and Design, 11th Congress of the French Chemical Engineering Society, 86 (6): 554-59.

Mori, M., Seyssiecq I., and Roche N., 2006. "Rheological Measurements of Sewage Sludge for Various Solids Concentrations and Geometry." Process Biochemistry 41 (7): 1656-62.

Nielsen, P., Frolund B., and Keiding K., 1996. "Changes in the Composition of Extracellular Polymeric Substances in Activated Sludge during Anaerobic Storage." Applied Microbiological Biotechnology 44.

Ohm, T.-I.,Chae,J.-S., Kim, J.-E., Kim, H., and Moon, S.-H., 2009. "A study on the dewatering of industrial waste sludge by fry-drying technology." Journal of Hazardous Materials 168 (1): 445-450.

O’Kelly, B. C., 2005. “Mechanical Properties of Dewatered Sewage Sludge." Waste Management 25 (1): 47-52.

O’Kelly, B. C., 2006. "Geotechnical properties of municipal sewage sludge." Geotechnical and Geological Engineering, no. 24: 833-50.

O'Kelly, B. C., 2008. "Effect of Biodegradation on the Consolidation Properties of a Dewatered Municipal Sewage Sludge." Waste Management 28 (8): 1395-1405. 
Papadakis, S.E. and Bahu, R.E., 1992. "The Sticky Issues of Drying." Drying Technology 10 (4): 817837.

Pelletier, A., Worcel A., and Terver S., 1998. "Design, Realisation and Validation of a Non-Destructive Cyclical Uniaxial Mechanical Compression Test." Journal of Biomechanics, Proceedings of the 11th Conference of the European Society of Biomechanics, 31, Supplement 1: 136.

Peeters, B., Dewil, R., Van Impe, J.F., Vernimmen, L., and Smets, I.Y., 2010. "Using a Shear Test Based Lab Protocol to Map the Sticky Phase of Activated Sludge." Environmental Engineering Science 28 (1): 81-85.

Pevere, A., Guibaud G., Goin E., Van Hullebusch E., and Lens P., 2009. "Effects of Physico-Chemical Factors on the Viscosity Evolution of Anaerobic Granular Sludge." Biochemical Engineering Journal 43 (3): 231-38.

Ramírez-Wong, B., Sweat V. E., Torres P. I., and Rooney L. W., 1996. "Evaluation of the Rheological Properties of Fresh Corn Masa Using Squeezing Flow Viscometry: Biaxial Extensional Viscosity1." Journal of Texture Studies 27 (2): 185-98.

Ratkovich, N., Horn W., Helmus F. P., Rosenberger S., Naessens W., Nopens I., and Bentzen T. R., 2013. "Activated Sludge Rheology: A Critical Review on Data Collection and Modelling." Water Research 47 (2): 463-82.

Roudot, A. C. 2002. Rheology and analysis of food texture (in French, Rhéologie et analyse de texture des aliments.) Paris: TEC \& DOC.

Ruiz, T., Kaosol T., and Wisniewski C., 2010. "Dewatering of Urban Residual Sludges: Filterability and Hydro-Textural Characteristics of Conditioned Sludge." Separation and Purification Technology 72 (3): 275-81.

Ruiz, T., and Wisniewski C., 2008. "Correlation between Dewatering and Hydro-Textural Characteristics of Sewage Sludge during Drying." Separation and Purification Technology 61 (2): 204-10.

Ségalen, C., Dieudé-Fauvel E., and Baudez J.C., 2015. "Electrical and Rheological Properties of Sewage Sludge - Impact of the Solid Content." Water Research, Special Issue on Sludge Research, 82 (October): 25-36.

Seyssiecq, I., Ferrasse J.H., and Roche N., 2003. "State-of-the-Art: Rheological Characterisation of Wastewater Treatment Sludge." Biochemical Engineering Journal 16 (1): 41-56.

Sharma, P. K., H. J. Busscher, T. Terwee, S. A. Koopmans, and T. G. van Kooten. 2011. "A Comparative Study on the Viscoelastic Properties of Human and Animal Lenses." Experimental Eye Research 93 (5): 681-88.

Sharma, S., and Bhattacharya S., 2014. "Strain and Strain Rate Dependence of Gellan, Agar and Agargellan Gels as Model Systems." Journal of Food Engineering 141 (November): 93-98.

Steffe, J., 1996. Rheological Methods in Food Process Engineering. USA: Freeman Press.

Sveegaard, S.G., Keiding, K., and Christensen, M.L., 2012. "Compression and swelling of activated sludge cakes during dewatering." Water Research 46 (16): 4999-5008.

Wolny, L., Wolski P., and Zawieja I., 2008. "Rheological Parameters of Dewatered Sewage Sludge after Conditioning." Desalination, European Desalination Society and Center for Research and Technology Hellas (CERTH), Sani Resort 22 -25 April 2007, Halkidiki, Greece European Desalination Society and Center for Research and Technology Hellas (CERTH), Sani Resort, 222 (1-3): 382-87.

Yen, P.S., Chen L.C., Chien C.Y., Wu R.M., and Lee D. J., 2002. "Network Strength and Dewaterability of Flocculated Activated Sludge." Water Research 36 (3): 539-50.

Yu, J., Santos P.H.S., and Campanella O.H., 2012. "A Study to Characterize the Mechanical Behavior of Semisolid Viscoelastic Systems Under Compression Chewing - Case Study of Agar Gel." Journal of Texture Studies 43 (6): 459-67.

Zhang, C., Cao P., Pu C., Liu J., and Wen P., 2014. "Integrated Identification Method of Rheological Model of Sandstone in Sanmenxia Bauxite." Transactions of Nonferrous Metals Society of China 24 (6): 1859-65. 


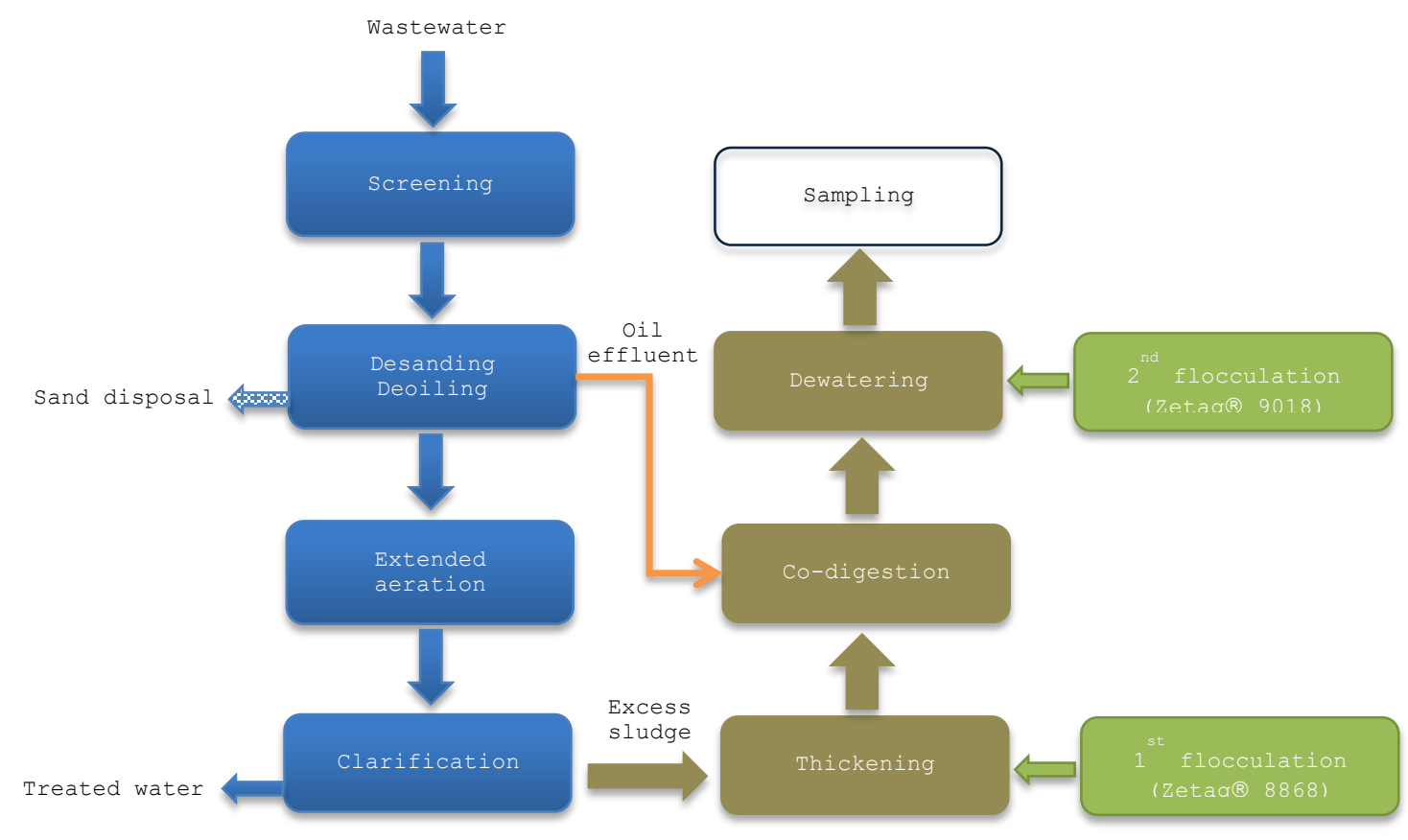

638 Figure 1: Municipal wastewater treatment process at Albi WWTP, the location of the mechanically 639 dewatered sludge samples collected for rheological characterisation

640

641 
642

643

644

645

646 647
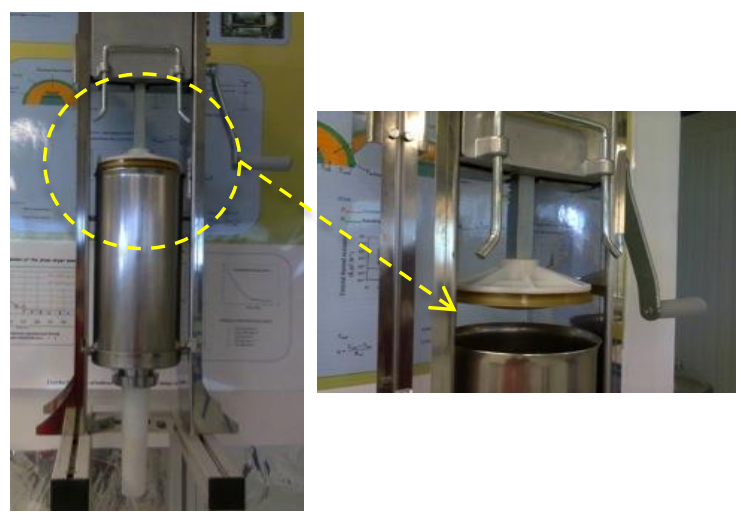

(a)

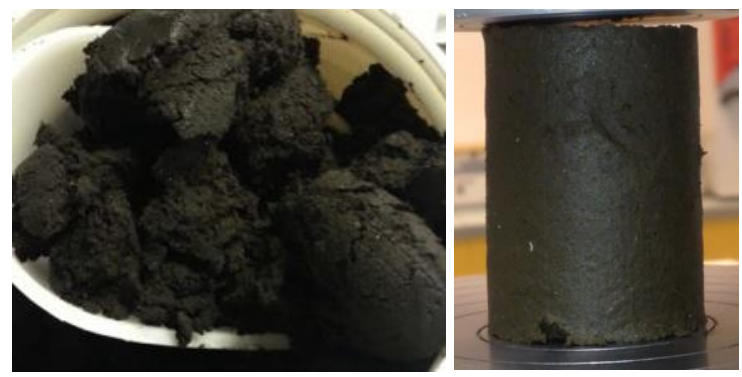

(c)

Figure 2: (a) Manual extruder (b) Original sludge samples before shaping (c) Extruded sludge sample 

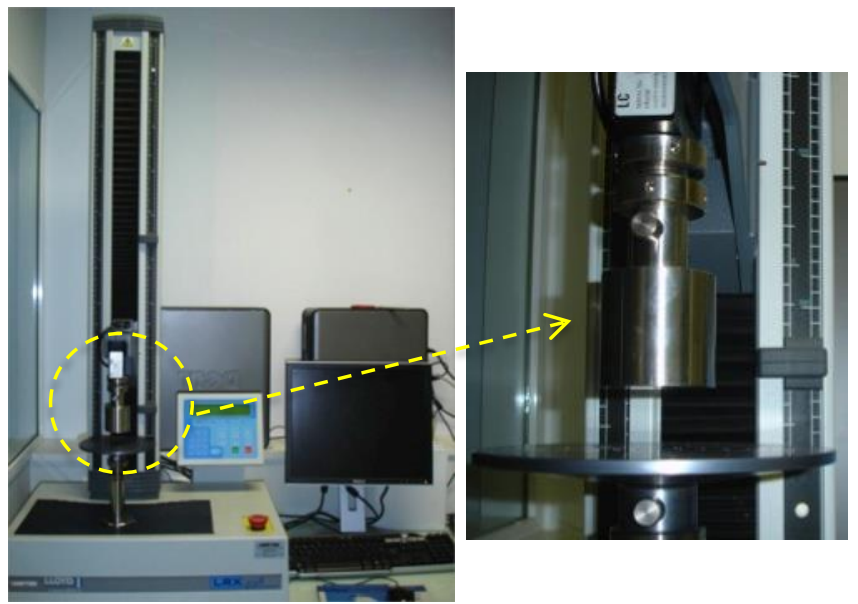

Figure 3: Universal testing machine

654

655 


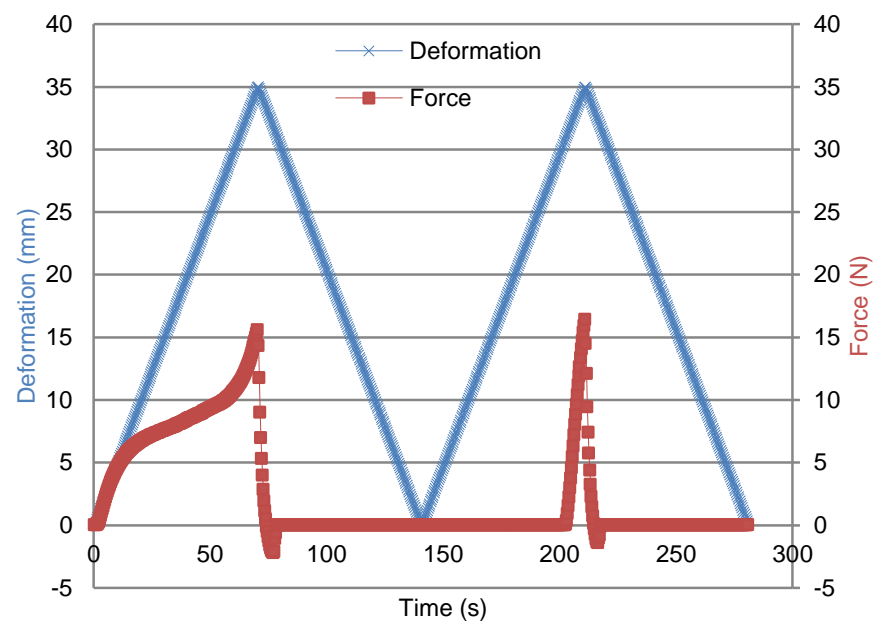

657

658

659

660

661
Figure 4: Mechanical response to a uniaxial cyclical compression test with $\Delta \mathrm{h}_{\max }=35 \mathrm{~mm}$ and $\mathrm{V}=0.5 \mathrm{~mm} / \mathrm{s}$ 


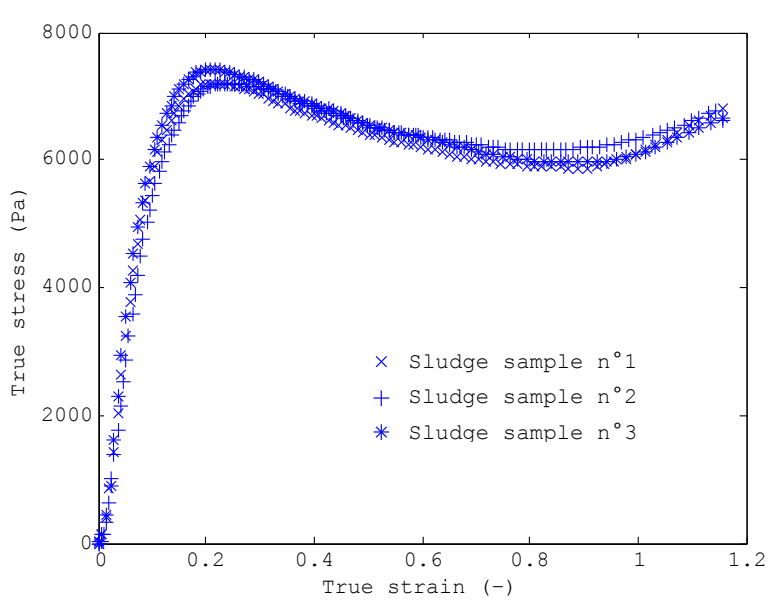

(a)

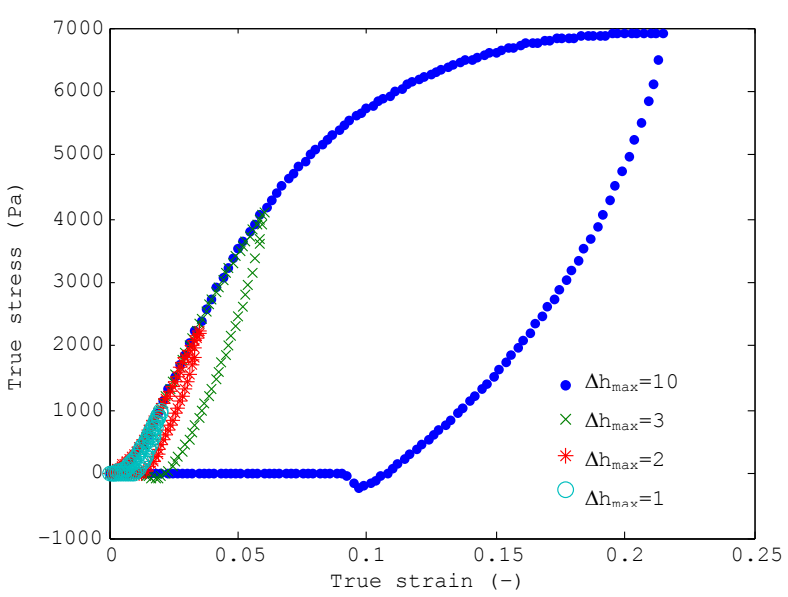

(c)

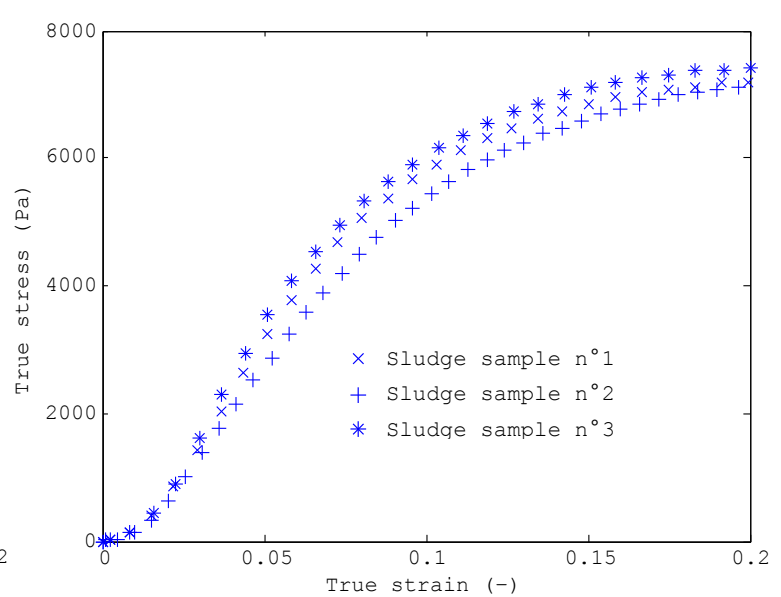

(b)

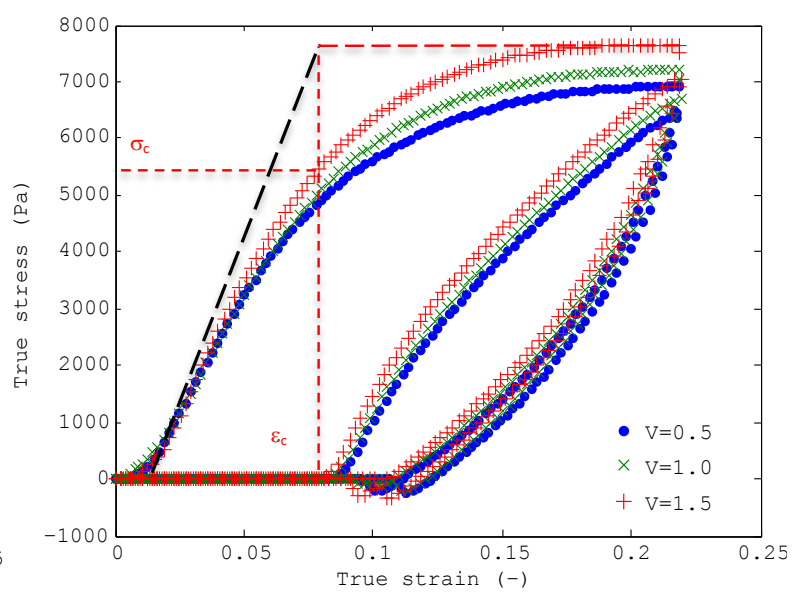

(d)

Figure 5: (a) Single compression curves for 3 identical fresh raw sludge samples with $\Delta \mathrm{h}_{\max }=35 \mathrm{~mm}$ and $\mathrm{V}=0.5 \mathrm{~mm} / \mathrm{s}$; (b) zoomed out curves $(0<\varepsilon<0.2)$ in (a); (c) 1 cycle compression tests on 4 identical original sludge with $V=0.5 \mathrm{~mm} / \mathrm{s}$ and $\Delta \mathrm{h}_{\max }=1,2,3$ and $10 \mathrm{~mm}$; (d) 2 consecutive cycles compression tests on 3 identical original sludge with $\Delta \mathrm{h}_{\max }=10 \mathrm{~mm}$ and $\mathrm{V}=0.5,1.0$ and $1.5 \mathrm{~mm} / \mathrm{s}$, and estimation of yield stress $\sigma_{c}$ and strain $\varepsilon_{c}$ (using regressed lines for ideal elastic and plastic behaviors) 
665

666

667

668

669

670

671

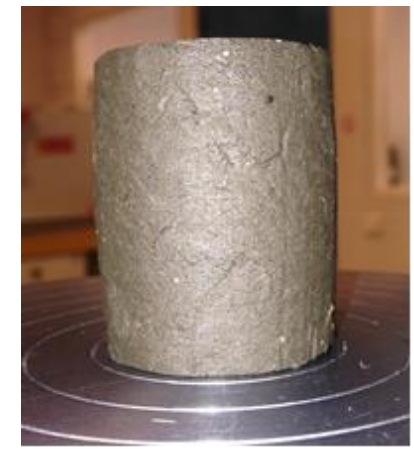

(a)



(b)

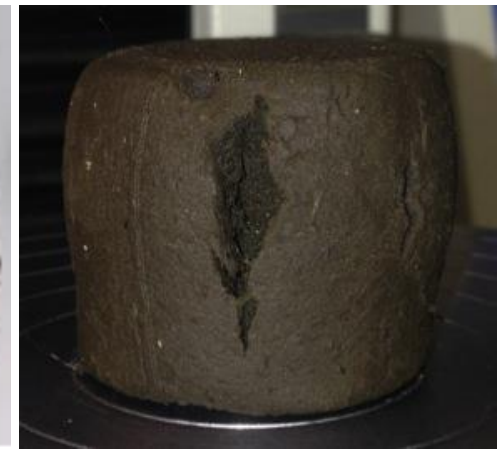

(c)

Figure 6: (a) Non-fractured sludge sample after compression test; (b) tested sludge sample cut into slice for internal crack detection: no internal fracture observed; (b) fractured sludge sample after compression test 


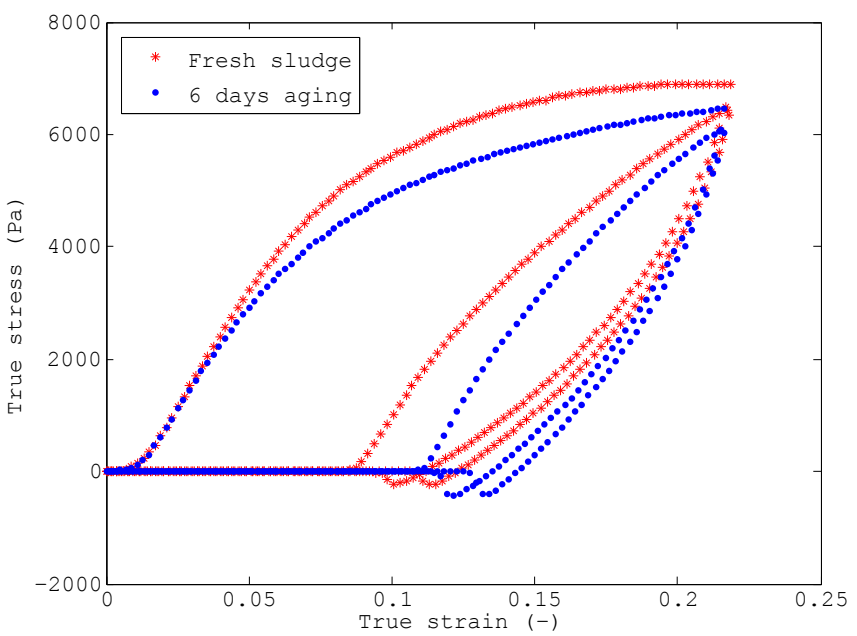


677

678

679

680

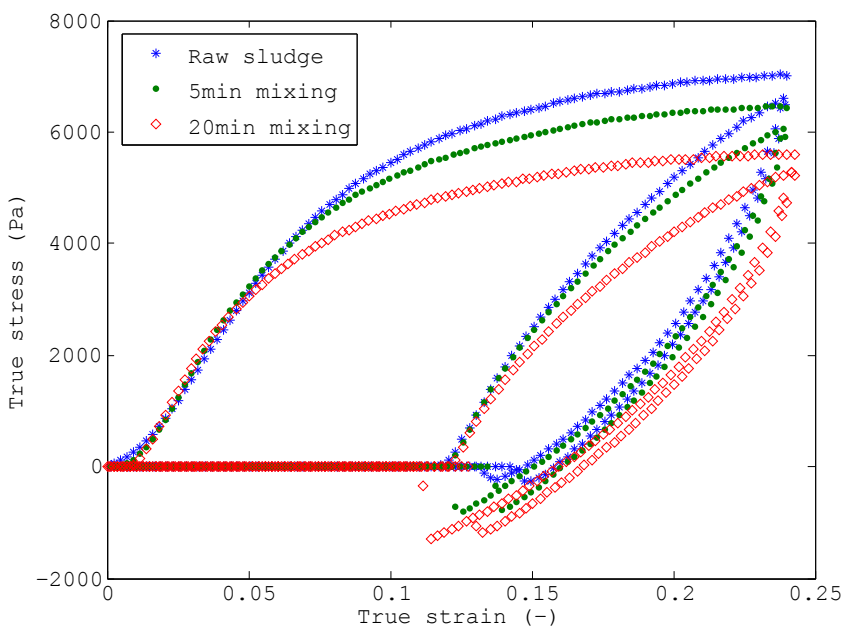

Figure 8: Influence of premixing on sludge behavior with $\Delta \mathrm{h}_{\max }=10 \mathrm{~mm}$ and $V=0.5 \mathrm{~mm} / \mathrm{s}$ 